\title{
Absorption loss at nanorough silver back reflector of thin-film silicon solar cells
}

\author{
J. Springer, ${ }^{\text {a) }}$ A. Poruba, L. Müllerova, and M. Vanecek \\ Institute of Physics, Academy of Sciences of the Czech Republic, Cukrovarnicka 10, CZ-16253, \\ Prague 6, Czech Republic \\ O. Kluth and B. Rech \\ Institute of Photovoltaics, Forschungszentrum Jülich GmbH, D-52425 Jülich, Germany
}

(Received 8 September 2003; accepted 24 October 2003)

\begin{abstract}
Absorption losses at a nanorough silver back reflector of a solar cell were measured with high accuracy by photothermal deflection spectroscopy. Roughness was characterized by atomic force microscopy. The observed increase of absorption, compared to the smooth silver, was explained by the surface plasmon absorption. Two series of silver back reflectors (one covered with thin $\mathrm{ZnO}$ layer) were investigated and their absorption related to surface morphology. (C) 2004 American Institute of Physics. [DOI: 10.1063/1.1633652]
\end{abstract}

\section{INTRODUCTION}

A rough silver back reflector is used in thin-film silicon solar cells to reflect and scatter light, which was not absorbed during the first path through the very thin solar cell. The roughness on a scale of $20-200 \mathrm{~nm}$ [root mean square (rms) value] serves to scatter the light, in order to increase the optical path of weakly absorbed light in the cell. ${ }^{1-3}$ In combination with the light trapping effect in a medium (silicon) with a high index of refraction, it increases the current generated in thin-film silicon solar cells, leading to efficiencies over $14 \%$ in thin amorphous $\mathrm{Si} /$ microcrystalline $\mathrm{Si}$ tandem. ${ }^{2,4}$

Optical properties of thin-film silicon solar cells with nanorough interfaces were modeled. ${ }^{5-7}$ These models ask for the accurate optical constants of materials used in the solar cells. They are well known for different forms of silicon (amorphous, microcrystalline, and crystalline) and $\mathrm{ZnO}$ with various doping levels, ${ }^{5,8,9}$ but no precise spectral study has been done for the rough silver surface, covered by a thin $\mathrm{ZnO}$ layer-the best back reflector for thin-film silicon solar cells. A lower total reflectance of the rough metal surface compared to the smooth one was observed ${ }^{1,5,10-12}$ but without a sufficient accuracy required, since a part of the scattered light is backreflected several times into the cell and, therefore, an error in the determination of the absorption losses accumulates.

In this article, we present the spectra of the total absorption loss (absorptance $A$ ) of nanorough silver surfaces measured with high accuracy. Instead of the measurement of the total reflectance $R$ and calculation of $A=(1-R)$, we measure $A$ directly, using photothermal deflection spectroscopy (PDS). This helps us to increase the precision of measurement for the most important case of weak absorption losses (under 10\%), as discussed below. The range 4-150 nm of rms roughness is covered. Roughness is determined by atomic force microscopy (AFM).

\footnotetext{
a)Electronic mail: springer@fzu.cz
}

\section{EXPERIMENTAL DETAILS}

The PDS measurement ${ }^{13}$ (Fig. 1) was done in $\mathrm{CCl}_{4}$. Results were compared to the total reflectance measurement of a standard spectrometer. The PDS measurement requires a procedure for the absolute calibration of PDS data, which will be described below. This enables a very accurate measurement of $A$ with an absolute error of about $0.5 \%$ which is one order of magnitude lower than can be reached with a spectrometer equipped by an integrating sphere (compare the error bars in Fig. 2 versus Figs. 4 and 5). We measure a PDS spectrum in the spectral range $0.8-4.5 \mathrm{eV}(1550-276 \mathrm{~nm})$. This provides a highly precise absorptance $A$ spectrum over the entire region, however, on a relative scale. ${ }^{13}$ In order to set this result into an absolute scale, we need to fix one point. We use the (bulk) plasma edge of silver at $316 \mathrm{~nm}$, where the reflectance in air sharply drops below 1\% (for a typical low spectral resolution, high light throughput PDS apparatus, it drops to 6\%). This is a bulk effect, not affected by the surface roughness. This experimental value is in a good agreement (Fig. 2) with the one calculated, using the data of smooth bulk silver. ${ }^{14}$ It yields the silver reflectance of $7 \%$ in $\mathrm{CCl}_{4}$. Hence, we normalize our relative absorptance PDS data to be $93 \%$ at $316 \mathrm{~nm}(3.92 \mathrm{eV})$. The expected error of $A$ resulting from this normalization is lower than an absolute error in the PDS spectrum.

Preparation of the nanotextured back reflectors involves three steps. First, the $\mathrm{ZnO}$ film was deposited on glass by sputtering. This film, initially "flat," [rms roughness $<15 \mathrm{~nm}$, Fig. 3(a)] develops a surface texture upon etching in diluted $\mathrm{HCl}^{8,15,16}$ The surface roughness can be varied by varying the etching time. Such textured $\mathrm{ZnO}$ films were coated with $500 \mathrm{~nm}$ thick Ag films also prepared by sputtering. The surface texture of $\mathrm{ZnO}$ is maintained and thus the rms roughness of the Ag films in the range of $14-150 \mathrm{~nm}$ was reached (Fig. 3).

Our samples show a combination of the "flat" surface and etched craters. For the longest etching time of $\mathrm{ZnO}$, the flat surface completely disappears. Additionally, we prepared 


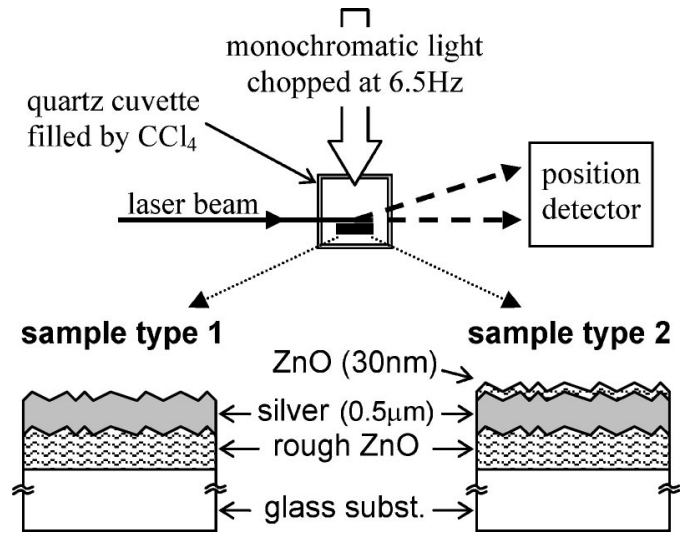

FIG. 1. Experimental setup for PDS. Probe laser beam is periodically deflected due to the thermally induced refractive index gradient of $\mathrm{CCl}_{4}$. Deflection angle is proportional to the total absorptance of sample. We measured two types of samples, sketched above.

two samples with a smooth silver surface as a reference: Silver sputtered directly on the Corning glass (rms roughness $=4.2 \mathrm{~nm}$ ) and silver sputtered on a thin nonetched $(30 \mathrm{~nm}) \mathrm{ZnO}$ layer $(\mathrm{rms}$ roughness $=5.5 \mathrm{~nm})$. Since the silver surface is sensitive to an ambient atmosphere, we kept the samples in the nitrogen atmosphere. Furthermore, the second series of samples was covered by $30 \mathrm{~nm}$ of $\mathrm{ZnO}$ (Fig. 1 , sample type 2).

\section{RESULTS}

Experimental data obtained for both series are presented in Figs. 4-6. Our results show that the absorptance $A$ (measured from the plasma edge in ultraviolet region down to the infrared) is not a simple function of the rms roughness. Back reflectors in silicon (amorphous and microcrystalline) solar cells operate between 500 and $1100 \mathrm{~nm}$. The lowest absorption loss in this region is for the silver layer deposited directly on a glass substrate (Fig. 4, dashed line). Absorptance is already higher for silver deposited on an almost smooth (nonetched) $\mathrm{ZnO}$ layer independent of the surface rms roughness $(5.5 \mathrm{~nm}$ and $14 \mathrm{~nm})$ and increases for $\mathrm{ZnO}$-etched

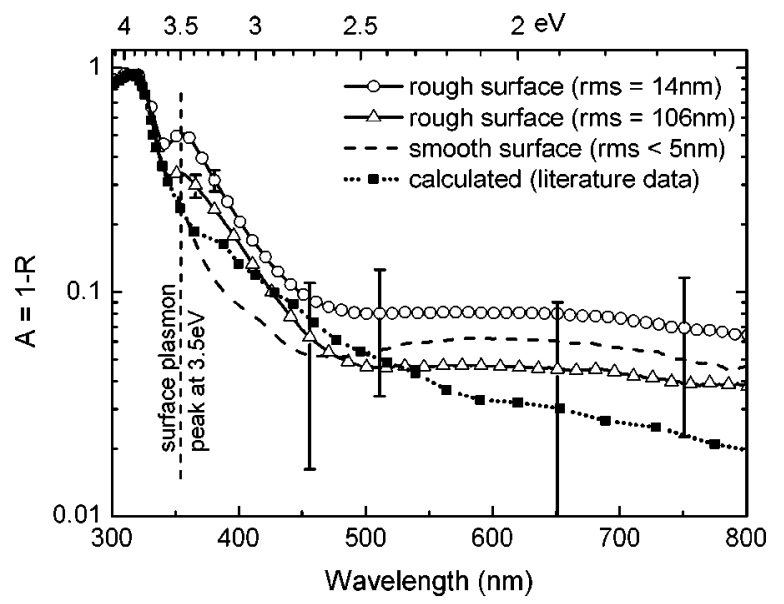

FIG. 2. Absorptance $A$ of rough silver surface evaluated as $(1-R)$ from a spectrometer measurement with an integrating sphere. Expected relative error is $5 \%$ in the total reflectance $R$. The measurements are compared to the calculated values using literature data (see Ref. 13). (a) $r m s=14 \mathrm{~nm}$
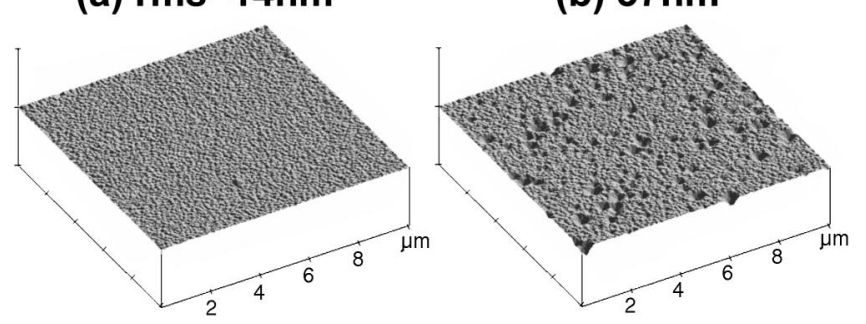

(c) $74 \mathrm{~nm}$

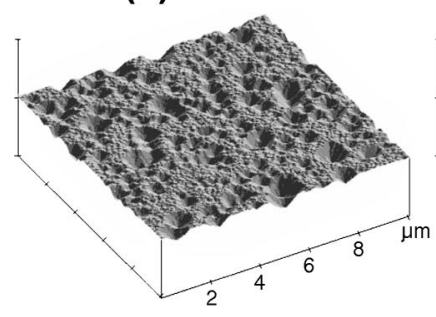

(d) $106 \mathrm{~nm}$

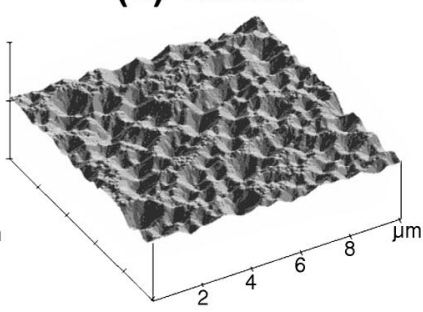

(e) $131 \mathrm{~nm}$

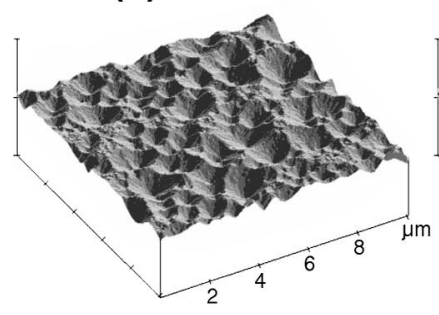

(f) $146 \mathrm{~nm}$

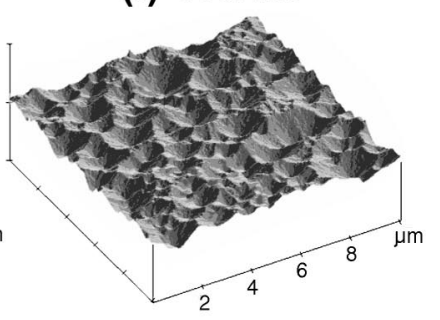

FIG. 3. AFM topography of silver surfaces deposited on smooth or rough $\mathrm{ZnO}$ (thickness $450-600 \mathrm{~nm}$ ). The surface roughness was modified by varying etching time (see Refs. 7 and 15); the value of rms roughness is shown.

samples with craters $(37-146 \mathrm{~nm})$. A similar trend is for silver covered by $30 \mathrm{~nm} \mathrm{ZnO}$ layer (Fig. 5). For the roughness larger than approximately $35 \mathrm{~nm}(\mathrm{rms})$, the absorptance saturates for both series (Fig. 6). The type of the sublayer is also important (compare $\mathrm{Ag}$ deposited on $\mathrm{ZnO}$ and glass with a similar shape and the rms roughness, Fig. 4 dashed lines).

We observe a shift in the position of the absorption peak. Figure 2 shows its position $3.5 \mathrm{eV}$ for a $\mathrm{Ag}$ surface measured

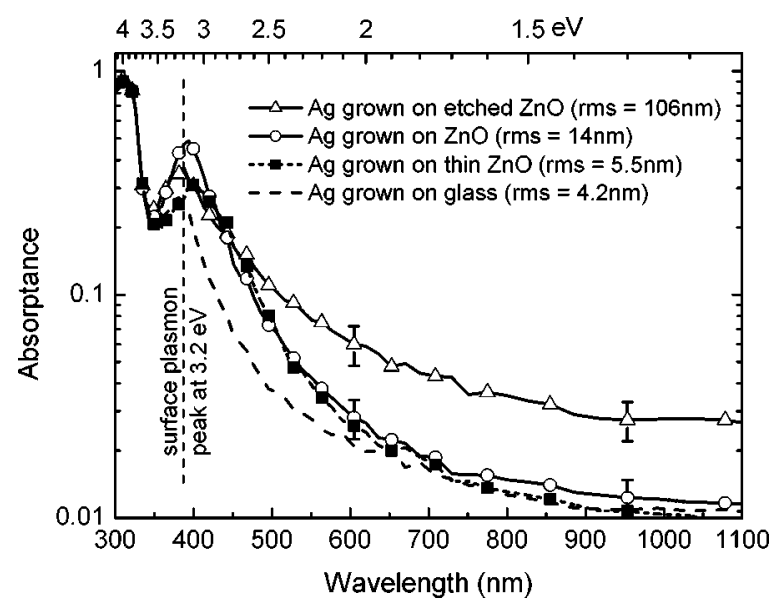

FIG. 4. Absorptance $(A)$ spectra of rough silver surfaces as measured by PDS. Ag is in contact with $\mathrm{CCl}_{4}$. Symbols show every third measured value. Expected relative error is $20 \%$ of the $A$. 


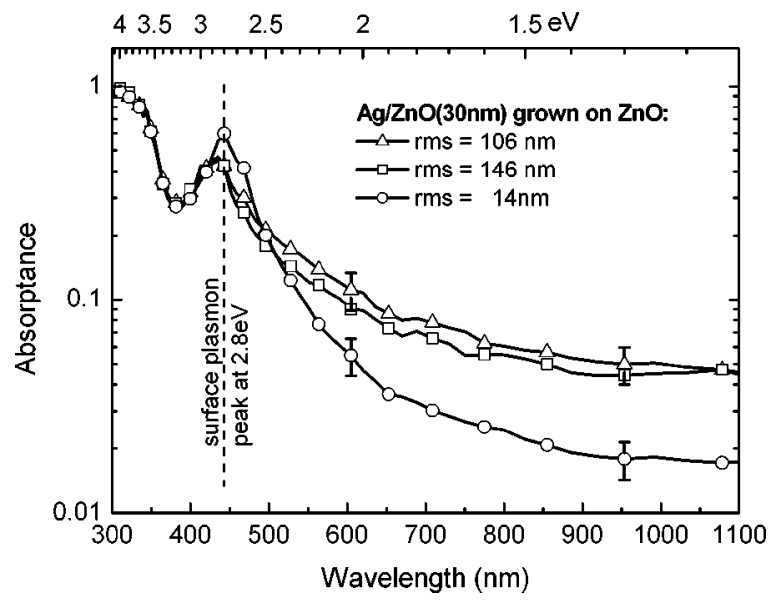

FIG. 5. Absorptance $(A)$ spectra of rough silver surfaces covered by $30 \mathrm{~nm}$ $\mathrm{ZnO}$ (sample type 2), as measured by PDS. Symbols show every third measured value. Expected relative error is $20 \%$ of the $A$.

in air. The position moves to 3.2 and $2.8 \mathrm{eV}$ for the PDS measurement of $\mathrm{Ag}$ and $\mathrm{Ag} / \mathrm{ZnO}(30 \mathrm{~nm})$ surface, respectively (Figs. 4 and 5). The peak is sharper for back reflectors deposited on nonetched $\mathrm{ZnO}(\mathrm{rms}=14 \mathrm{~nm})$ than on etched $\mathrm{ZnO}(\mathrm{rms}>20 \mathrm{~nm})$.

\section{DISCUSSION}

We explain the measured data with the help of the surface plasmon (SP) theory. ${ }^{17-19}$ An observed peak in absorption (dip in reflection) at about $320 \mathrm{~nm}$ corresponds to the (volume) plasma edge, another (weaker) resonance around $400 \mathrm{~nm}$ is due to the SP. This SP resonance moves toward the longer wavelengths when the dielectric, which is in contact with the rough $\mathrm{Ag}$ layer, has a higher index of refraction. This can be seen when comparing the peak position of the SP in Figs. 2, 4, and 5 where the corresponding refractive indexes of air, $\mathrm{CCl}_{4}$, and $\mathrm{ZnO}$ are about 1, 1.5, and 2.1, respectively. This is just what should be expected for the SP resonance. ${ }^{17}$ The case of low Ag surface roughness, below 10

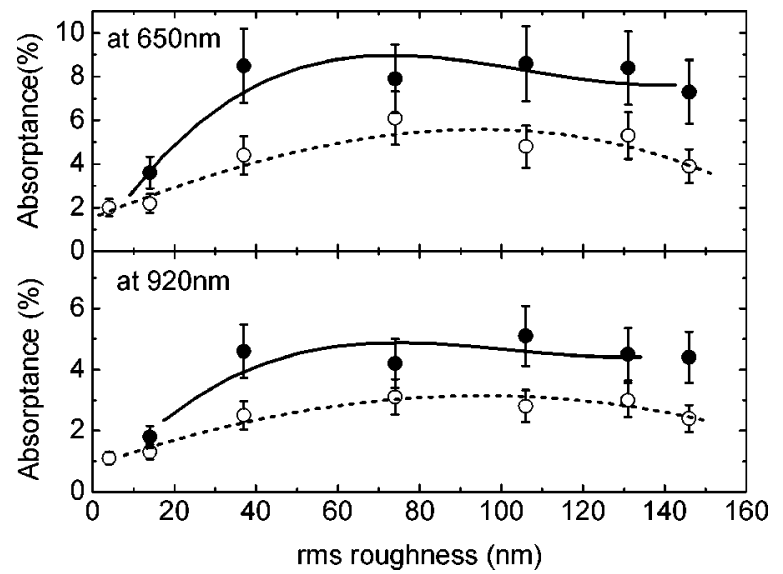

FIG. 6. Summary of absorptance values for rough $\mathrm{ZnO} / \mathrm{Ag}$ surfaces (full symbols) and Ag surfaces (open symbols) at 650 and $920 \mathrm{~nm}$, as a function of the surface roughness. $\mathrm{nm}$, was already examined by Harbeke ${ }^{18}$ who observed a resonant absorption (dip in reflection $R$ ) at $350 \mathrm{~nm}$ for the interface $\mathrm{Ag} / \mathrm{air}$.

Low absorption loss in spectral region $500-1100 \mathrm{~nm}$ is necessary for high efficiency of thin-film silicon solar cells. The broad SP peak increases absorption in this region. It can be influenced by the selection of dielectrics between the silicon absorber and silver and by the surface morphology. Further studies of optimal surface morphology to reduce losses, while keeping good light scattering properties of nanorough silver surface, are underway.

\section{CONCLUSION}

To conclude, we directly measured absorption losses in rough silver back reflectors, with a high precision in the spectral region of interest for thin-film silicon solar cells (500-1100 nm). Absorption loss did not scale directly with an increasing surface roughness and the saturation is observed. PDS as presented here proved to be a useful tool for this study.

\section{ACKNOWLEDGMENTS}

The work was supported by the project DOIT of European Communities, Contract No. ENK6-CT2000-00321 and by the Czech research program K1010104.

${ }^{1}$ J. Morris, R. R. Arya, J. G. O’Down, and S. Wiedeman, J. Appl. Phys. 67, 1079 (1990).

${ }^{2}$ A. V. Shah, H. Schade, M. Vanecek, J. Meier, E. Vallat-Sauvain, N. Wyrsch, U. Kroll, C. Droz, and U. Graf, Prog. Photovoltaics (to be published).

${ }^{3}$ A. Poruba, A. Fejfar, Z. Remes, J. Springer, M. Vanecek, J. Kocka, J. Meier, P. Torres, and A. Shah, J. Appl. Phys. 88, 148 (2000).

${ }^{4}$ K. Yamamoto, A. Nakajima, M. Yoshimi, T. Sawada, S. Fukuda, K. Hayashi, T. Suezaki, M. Ichikawa, Y. Koi, M. Goto, H. Takata, and Y. Tawada, Proceedings of the 29th IEEE PVSC, New Orleans, LA, (2002), p. 1110.

${ }^{5}$ J. Springer, A. Poruba, M. Vanecek, S. Fay, L. Feitknecht, N. Wyrsch, J. Meier, A. Shah, T. Repmann, O. Kluth, H. Stiebig, and B. Rech, Proceedings of the 17th E-PVSEC, Munich, Germany (2002), p. 2830.

${ }^{6}$ J. Krc, M. Zeman, F. Smole, and M. Topic, J. Appl. Phys. 92, 749 (2002).

${ }^{7}$ Y. Hishikawa, T. Kinoshita, M. Shima, M. Tanaka, S. Kiyama, S. Tsuda, and S. Nakano, Proceedings of the 26th IEEE PVSC, Anaheim, CA, (1997), p. 615.

${ }^{8}$ O. Kluth, O. Vetterl, R. Carius, F. Finger, S. Wieder, B. Rech, and H. Wagner, Mater. Res. Soc. Symp. Proc. 557, 731 (1999).

${ }^{9}$ J. Meier, J. Spitznagel, S. Fay, C. Bucher, U. Graf, U. Kroll, S. Dubail, and A. Shah, Proceedings of the 29th IEEE PVSC, New Orleans, LA, (2002), p. 1118

${ }^{10}$ H. Stiebig, T. Brammer, T. Repmann, O. Kluth, N. Senoussaoui, A. Lambertz, and H. Wagner, Proceedings of the 16th E-PVSEC, Glasgow, UK, (2000), p. 549

${ }^{11}$ A. Banerjee and S. Guha, J. Appl. Phys. 69, 1030 (2002).

${ }^{12} \mathrm{X}$. Deng and K. L. Narasimhan, Proceedings of the First WCPEC, Hawaii, (1994), p. 555.

${ }^{13}$ N. M. Amer and W. B. Jackson, in Hydrogenated Amorphous Silicon Vol. 21, part B, edited by J. I. Pankove, (Academic, Orlando, 1984), p. 83

${ }^{14}$ D. W. Lynch and W. R. Hunter, in Handbook of Optical Constants of Solids, edited by E. D. Palik (Academic, Orlando, 1985), p. 350.

${ }^{15}$ B. Rech, O. Kluth, T. Repmann, T. Roschek, J. Springer, J. Müller, F. Finger, H. Stiebig, and H. Wagner, Solar Energy Mater. Solar Cells 74, 439 (2002).

${ }^{16}$ O. Kluth, B. Rech, L. Houben, S. Wieder, G. Schöpe, C. Beneking, H. Wagner, A. Löffl, and H. W. Schock, Thin Solid Films 351, 247 (1999).

${ }^{17}$ H. Raether, in Surface Plasmons on Smooth and Rough Surfaces and on Gratings Springer Tracts in Modern Physics Vol. 111, (Springer, Berlin, 1988).

${ }^{18}$ G. Harbeke, in Polycrystalline Semiconductors, edited by G. Harbeke (Springer, Berlin, 1985), p. 156.

${ }^{19}$ E. Fontana and R. H. Pantell, Phys. Rev. B 37, 3164 (1988). 